\title{
The Response of Two Types of Sclerotium rolfsii to Factors Affecting Sclerotium Formation
}

\author{
By I. CHET AND Y. HENIS \\ Department of Plant Pathology and Microbiology \\ The Hebrew University of Jerusalem, Faculty of Agriculture Rehovot, Israel
}

(Received I3 April 1972; revised 25 June 1972)

\section{SUMMARY}

Ten isolates of Sclerotium rolfsii were divided into two types ( $\mathrm{R}$ and $\mathrm{A}$ ) which differed in their response to factors affecting sclerotium formation. It is suggested that differences in carbohydrate metabolism may account for the differences between them.

\section{INTRODUCTION}

Many chemical and physical factors affect sclerotium formation in Sclerotium rolfsii Sacc. (Townsend \& Willetts, 1954; Chet, Henis \& Mitchell, I966; Chet \& Henis, I968). Henis \& Chet (1968) suggested that some of those involved in initiation, development and maturation of the sclerotia are of mycelial origin. However, no comparative information is available on the responses of various isolates of $S$. rolfsii to such factors.

\section{METHODS}

Ten isolates of Sclerotium rolfsii Sacc. from infected sugar beet, bean and potato plants were grown on a synthetic medium composed of $4 \%(\mathrm{w} / \mathrm{v})$ glucose, $0.02 \% \mathrm{MgSO}_{4} \cdot 7 \mathrm{H}_{2} \mathrm{O}$, $0.06 \% \mathrm{~K}_{2} \mathrm{HPO}_{4}, 0.02 \% \mathrm{KCl}, 0 . \mathrm{I} \% \mathrm{NH}_{4} \mathrm{NO}_{3}, 0.000 \mathrm{I} \%$ thiamine hydrochloride, $0.0002 \%$ $\mathrm{Fe}^{2+}, 0.0002 \% \mathrm{Mn}^{2+}, 0.0002 \% \mathrm{Zn}^{2+}$ and $2 \%(\mathrm{w} / \mathrm{v})$ Bacto agar $(\mathrm{pH} 6.8)$ and incubated at $30{ }^{\circ} \mathrm{C}$. Each experiment was carred out with five replicates.

\section{RESULTS AND DISCUSSION}

The isolates tested were divided into two types which differed in their morphological and physiological properties (Table I). Six isolates (collectively designed type $\mathrm{R}$ ) resembled the one used in our previous studies (Chet et al. I966), having a thick mycelium producing 80 to 100 sclerotia/plate, mostly near the plates' walls, after 6 to 7 days of incubation (Fig. I $a$ ).

The remaining four isolates (collectively designed type A) had a sparse mycelium and, after $72 \mathrm{~h}$, produced 500 to 600 sclerotia/plate, mainly in a band $18 \mathrm{~mm}$ wide, towards the periphery of the plate (Fig. I $b$ ). Hyphal-tip cultures were prepared from every isolate for three successive generations. All the isolates preserved their original characteristic morphology. When colonies of both types were grown together they showed a mutual growth inhibition (Fig. I $c$ ). When mycelium was transferred from the region of their contact, new types were not observed, suggesting no anastomoses formed between those types.

Although having a similar growth rate at $\mathrm{pH} 6 \cdot 8$, type A was more tolerant than type $\mathrm{R}$ to low pH values (Fig. 2) and its ability to form sclerotia was not affected, whereas type R 


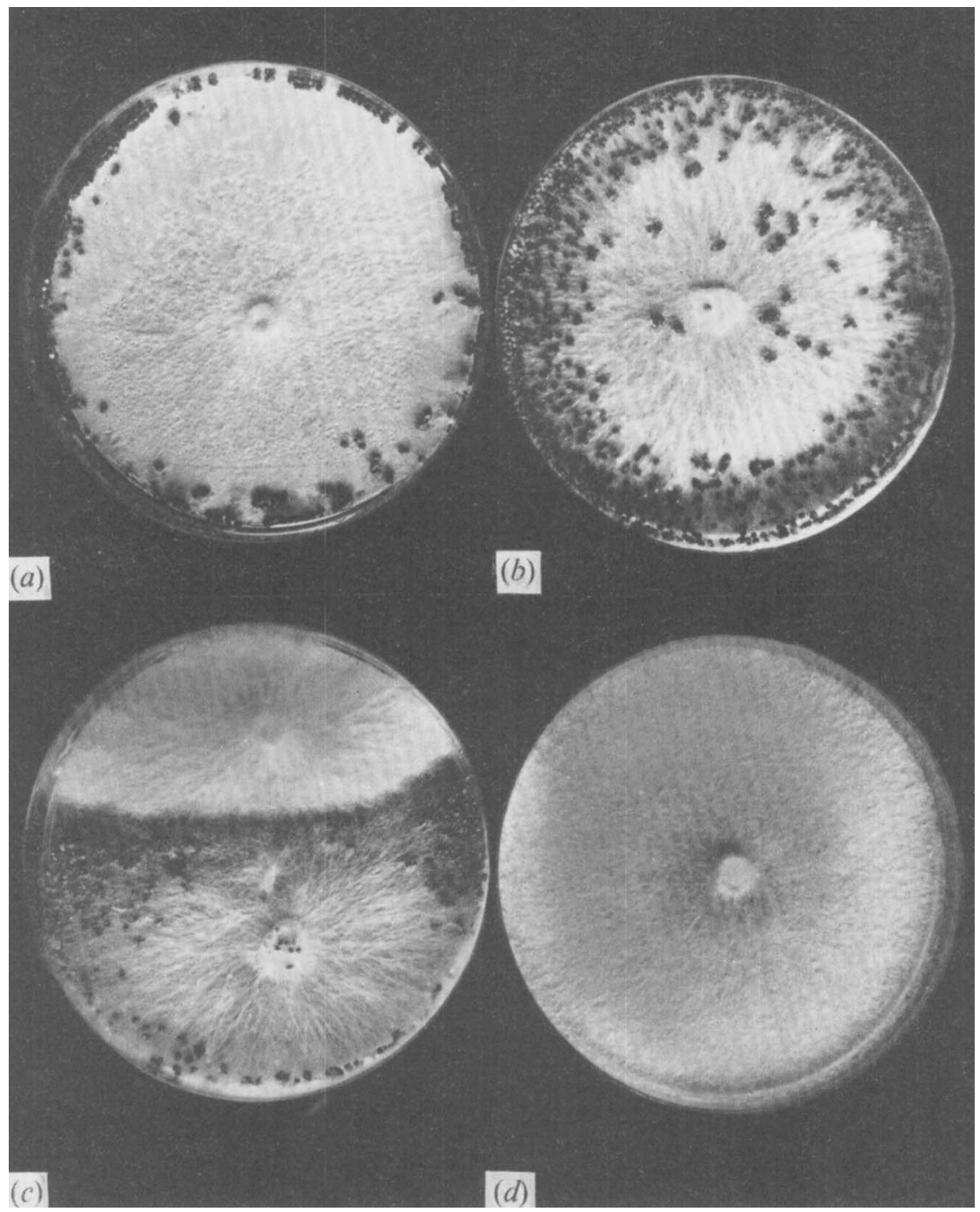

Fig. I. Type R (a) and A (b) grown on a synthetic medium for 8 days at $30^{\circ} \mathrm{C}$. (c) Types $\mathrm{R}$ (top and A (bottom) grown together on the same plate. $(d)$ The effect of $0.2 \% 2$-deoxy-D-glucose on type $\mathrm{R}$ (type A was identical with control).

produced only few sclerotia ( 10 to $\mathrm{I} 5$ /plate) at extremely low ( $\mathrm{pH} 3$ to 4 ) or high ( $\mathrm{pH} 9$ to Io) $\mathrm{pH}$ values. These types also differed in their response to compounds previously reported to affect sclerotium formation in Sclerotium rolfsii. Thus, sclerotium formation in type $\mathrm{R}$ was induced by iodoacetic acid (Chet et al. 1966) and by lactose (Okon, Chet \& Henis, 1972) and inhibited by cysteine (Chet et al. 1966), and by ethanol (Henis, Okon \& Chet, 1971), whereas the new type A was not affected by these compounds. When the lactose concentration was increased to $1 \cdot 5 \%(\mathrm{w} / \mathrm{v})$ and the glucose concentration was decreased to $0.5 \%(\mathrm{~L}+\mathrm{G}$ medium), mycelial growth and sclerotium formation of type R were inhibited, while type A continued to produce about 500 sclerotia/plate in a wide circular area. When 2-deoxy-Dglucose, a known antimetabolite of glucose in polysaccharide synthesis (Johnson, I968), was 


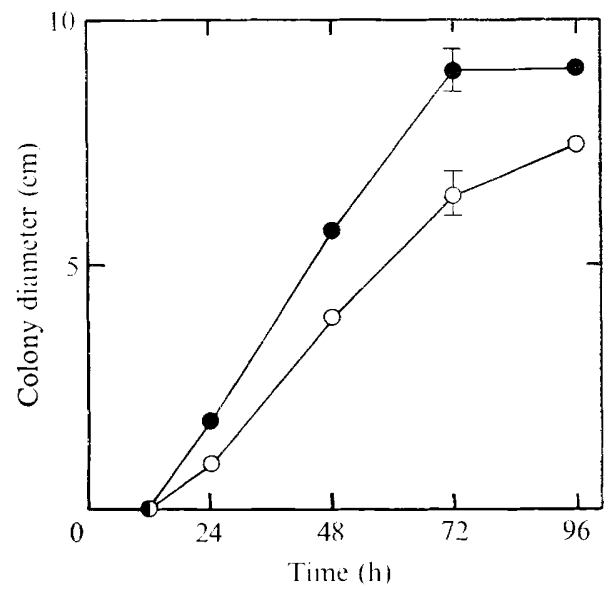

Fig. 2. Growth of type A (-O) and $\mathrm{R}(\mathrm{O}-\mathrm{O})$ on synthetic medium (see text), adjusted to $\mathrm{pH} 3$ with $\mathrm{HCl}$. The medium was prepared as a concentrated liquid and autoclaved separately from the agar. After cooling, the medium and agar were mixed.

Table I. The effect of various treatments on Sclerotium rolfsii strains (examined after i 5 days)

Treatment

Cysteine $\left(\mathrm{IO}^{-2} \mathrm{M}\right)$

Iodoacetic acid $\left(\mathrm{IO}^{-4} \mathrm{M}\right)$

Ethanol $(2$ to $4 \%, v / v)$

$\mathrm{G}+\mathrm{L}$ medium*

$\mathrm{L}+\mathrm{G}$ medium $\dagger$

2-Deoxy-D-glucose:

0.2 to $0.6^{\circ} \%$

0.7 to $1.0 \%$
Type A

Sclerotial intitials present

'Feather-like' mycelium, randomly spread sclerotia

Sclerotia randomly formed

Sclerotia randomly formed

Sclerotia formed in a circular area

No effect on sclerotium formation

Partial inhibition of mycelial growth and sclerotium formation
Type R

No sclerotia

Circle of sclerotia

No sclerotia formed

Circle of synchronous sclerotia formed

Partially inhibited mycelium, no sclerotia formed

Total inhibition of sclerotium formation

Partial mycelial inhibition, total inhibition of sclerotia

* Synthetic medium containing $1.5 \%$ (W/v) glucose and $0.5 \%$ lactose (Okon et al 1972 ).

$\uparrow$ Synthetic medium identical with $\mathrm{G}+\mathrm{L}$ but containing $1.5 \%(\mathrm{w} / \mathrm{v})$ lactose and only $0.5 \%$ glucose.

added to the synthetic medium it completely inhibited sclerotium formation in type $\mathrm{R}$ but did not so affect type A (Table 1), suggesting that the two types differed in their carbohydrate metabolism. Aycock ( I966) mentioned the presence of different morphological types of $S$. rolfsii. Our observations lead to the conclusion that the differences between type $\mathrm{R}$ and A were not only morphological, because sclerotium formation in type A, unlike that in type R, was not affected by the compounds tested. Furthermore, whereas growth and sclerotium formation in type $\mathrm{R}$ were independently affected, no such difference between the response of growth and sclerotium formation could be observed in type A. It is therefore possible that a control mechanism of sclerotium formation exists only in type R. A study of the physiological basis of this difference may lead to a better understanding of this mechanism in $S$. rolfsii. 


\section{REFERENCES}

Aycock, R. (1966). South rot and other diseases carried by Sclerotium rolfsii. North Carolina Agricultural Experiment Station. Technical Bulletin 174, 70-75.

Chet, I. \& Henis, Y. (1968). The control mechanism of sclerotial formation in Sclerotium rolfsii Sacc. Journal of General Microbiology 54, 23I-236.

Chet, I., Henis, Y. \& Mitchell, R. (I966). The morphogenetic effect of sulphur-containing amino acids, glutathione and iodoacetic acid on Sclerotium rolfsii Sacc. Journal of General Microbiology 45, 54I-546.

HeNIS, Y. \& CHET, I. (1968). Developmental biology of sclerotia of Sclerotium rolfsii. Canadian Journal of Microbiology 46, 947-948.

HeNis, Y., OKon, Y. \& CHET, I. (I97I). Effect of ethanol and lactose on formation of sclerotia by Sclerotium rolfsii. First International Congress of Mycology, Exeter, Abstracts, p. 43.

JoHnson, B. F. (1968). Lysis of yeast cell walls induced by 2-deoxyglucose at their sites of glucan synthesis. Journal of Bacteriology 95, 1169-1 172.

OKon, Y., Снет, I. \& HeNIS, Y. (1972). Lactose induced synchronous sclerotial formation in Sclerotium rolfsii and its inhibition by ethanol. Journal of General Microbiology 71, 465-470.

Townsend, B. B. \& WilletTs, A. J. (1954). The development of sclerotia of certain fungi. Transactions of British Mycological Society 37, 21 3-22I. 